RU Использование коммуникативного опыта

студентов педагогического направления

в обучении устной иноязычной речи

на основе функционально-познавательного подхода

\author{
Сердюк Е. В.
}

Аннотация. Целью исследования является определение места и роли опыта студентов-второкурсников - будущих учителей иностранного языка - в обучении монологической речи в языковом вузе. В статье рассматривается эмоциональный и интеллектуальный опыт студентов, на который может опираться преподаватель при обучении устной речи на основе функционально-познавательного подхода в педагогическом институте. Также отмечается доминирующий вид опыта при выполнении функциональных грамматически-ориентированных упражнений в рамках данного подхода. Научная новизна исследования заключается в систематизации типов упражнений по обучению студентов монологической речи с позиций функционально-познавательного подхода; даются инварианты побуждающих установок к заданиям целевого текста. Результат исследования заключается в обобщении и систематизации работы по обучению английской устной речи студентов педагогического направления и в систематизации различных типов упражнений с доминирующим видом опыта.

\title{
Using Pedagogical Students' Communicative Experience When Teaching Oral Foreign-Language Speech to Them on the Basis of Functional-Cognitive Approach
}

Serdyuk E. V.

\begin{abstract}
The paper aims to identify the role of students' communicative experience (second year, field of training "Pedagogical Education", profile "Foreign Language") in teaching foreign-language monologic speech. The article examines pedagogical students' emotional and intellectual experience which can be used when teaching oral foreign-language speech to them on the basis of the functional-cognitive approach. The researcher reveals a typology of functional grammar exercises constructed within this approach. Scientific originality of the study involves developing a typology of exercises focused on forming students' monologic speech skills. Examples of motivating pre-reading tasks are provided. The research findings are as follows: the author summarizes the experience of teaching English-language monologic speech to pedagogical students and proposes a typology of speech exercises.
\end{abstract}

\section{Введение}

Региональные языковые вузы готовят учителей английского, немецкого, французского и испанского языков. Многие студенты, особенно имеющие целевое направление, вернутся в свои районы, поселки, деревни для работы в школе. Известно, что учитель - это человек, который обучает других, учитель в отдаленных районах - особый феномен. Часто именно учитель становится примером для подражания во многих аспектах: поведении, отношении к людям, манере говорить и слушать. Это актуально для такого предмета, как «Иностранный язык». Именно грамматически правильная, эмоциональная, содержательная, выразительная речь учителя мотивирует обучающихся, позволяет им почувствовать красоту другого языка и иного способа выражения мыслей, открывает новое знание.

К иноязычной монологической речи учителя всегда предъявлялись повышенные требования. Особенности монолога, механизмы порождения устной речи, пути обучения монологу, комплекс упражнений давно 
являются предметом исследования методистов, психологов, лингвистов, педагогов (Н. Д. Гальскова, Н. И. Гез, М. В. Ляховицкий, А. А. Миролюбов, С. Ф. Шатилов, Р. К. Миньяр-Белоручев, И. А. Зимняя, Г.В.Рогова, Ф. М. Рабинович, Т. Е. Сахарова, С. И. Заремская, О. С. Богданова, Е. И. Пассов).

Для монолога характерны связность предложений, смысловая и композиционная организованность, содержательность, коммуникативная направленность, информативность, детализация, контекстность, а также индивидуальное построение, самостоятельность. Очевидно, что развитие умений монологической речи у студентов на занятиях по английскому языку требует большого количества часов аудиторной работы с преподавателем и практически невозможно без постоянного контроля со стороны преподавателя. Овладеть иноязычной монологической речью самостоятельно нельзя. В последнее время с введением новых образовательных стандартов для высшей школы и сокращением учебных часов на предметы практической направленности на младших курсах вуза произошли значительные изменения в распределении аудиторной и самостоятельной работы студентов в сторону критического уменьшения аудиторных часов работы. Однако существующие учебно-методические комплекты, рекомендованные к использованию в вузе для студентов педагогического направления, рассчитаны на гораздо бо́льшее количество часов контактной работы. Возникает разрыв, с одной стороны, между заложенными в программу часами на овладение устной речью и необходимым временем для развития умений монолога, а с другой - между количеством часов, на которое рассчитан учебник, и количеством академических часов в расписании. В таких условиях преподаватель нуждается в новых подходах к обучению иноязычной речи, что и обусловливает актуальность темы исследования.

Сейчас, как никогда ранее, преподаватель стоит перед необходимостью поиска более эффективных форм работы со студентами. Это не означает полный отказ от традиционных способов научения, целесообразность которых проверена временем. Речь идет о придании им бо́льшей интерактивности, обращении к эмоциональному и интеллектуальному опыту обучающихся, развитии самоанализа, самоконтроля и самоорганизации. Данное исследование обобщает многолетний опыт обучения монологической речи студентов - будущих педагогов.

Для достижения указанной цели исследования необходимо решить следующие задачи:

- дать определение понятию «опыт» как методической категории;

- раскрыть основные положения функционально-познавательного подхода, который лежит в основе обучения монологу в языковом вузе;

- рассмотреть типы упражнений по обучению устной речи;

- обозначить доминирующий вид опыта при развитии умений монологической речи на занятиях по английскому языку.

При решении поставленных задач были использованы следующие методы исследования: теоретический анализ научно-методической литературы, обобщение передового опыта обучения иностранным языкам, пробное обучение, опытное обучение.

Теоретической базой исследования послужили публикации зарубежных авторов Дж. Дьюи [10], Г. Драйдена, Дж. Воса [9], а также отечественных ученых (Л. С. Выготский, С. Т. Шацкий, Л. Н. Лесохина, Р. У. Богданова, Н. Ф. Голованова, Л. П. Буева, С. В. Христофоров), в которых рассматриваются образование через развитие опыта ученика, характер опытообразования, виды опыта, его содержание и структура.

Практическая значимость исследования заключается в том, что раскрываемый в статье комплекс упражнений по обучению устной речи студентов - будущих учителей английского языка может быть использован для более эффективного обучения монологической речи. Это также может способствовать развитию продуктивного сотрудничества между институтами педагогической направленности.

\section{Опыт как методическая категория}

Известно, что изучение любого иностранного языка невозможно без обращения к опыту самих студентов. С. И. Ожегов определяет опыт как «1. Отражение в сознании людей законов объективного мира и общественной практики, полученное в результате их активного практического познания. 2. Совокупность знаний и практически усвоенных навыков, умений. 3. Воспроизведение какого-нибудь явления экспериментальным путем, создание чего-нибудь нового в определенных условиях с целью исследования, испытания. 4. Попытка осуществить что-нибудь, пробное осуществление чего-нибудь» [16]. Опыт в психологии - «влияющие на сегодняшнее поведение моменты увиденного и пережитого, отложившиеся в процессе жизни и деятельности впечатления, убеждения, знания, умения и навыки человека, в том числе стиль его жизни, его привычки и автоматизмы» [23]. Опыт в философии - «1) философская категория, фиксирующая целостность и универсальность человеческой деятельности как единства знания, навыка, чувства, воли. Характеризует механизм социального, исторического, культурного наследования; 2) гносеологическая категория, фиксирующая единство чувственно-эмпирической деятельности» [15]. Опыт как педагогическая категория определяется как «интеграция уже имеющегося наличного знания с новым знанием на фоне рефлективной деятельности субъекта, полученным в результате практического взаимодействия с объектами окружающей действительности на трех уровнях: когнитивном, технологическом, ориентационном, при сохранении эмоционального фона события» [21, с. 183].

Интересным представляется синонимический ряд существительного «опыт»: искушенность, испытание, исследование, компетенция, навык, опытность, практика, умение, школа, эксперимент, эмпирия. Опыт 
возникает, когда человек преодолевает трудности, переживает жизненные ситуации и сохраняет о них значимые воспоминания в виде событий.

В терминах методики обучения иностранному языку опыт как переживания личности становится смыслообразующим, проявляется в актуальных деятельностях, регулирует потенциальные деятельности. Обратимся к типологии опыта, представленной Ю. И. Трофимовой. Исследователь выделяет следующие виды опыта:

- смысловой навыковый опыт;

- эмоционально-ассоциативный позитивно оцененный опыт;

- опыт ощущения личностной причастности, чувства собственного достоинства;

- опыт стремления быть вовлеченным в интригу событий;

- поликультурный (роднокультурный и инокультурный) опыт;

- рациональный опыт;

- опыт информативной насыщенности будущего поступочного поведения;

- опыт информативной предрасположенности к речевому акту;

- опыт внутриречевой активности;

- опыт в межличностных отношениях;

- опыт условных форм поведения;

- опыт самоутверждения [20, с. 230].

Данная типология является ценной для понимания потенциальных переживаний / мотивирующих состояний, которые испытывают студенты на занятии по практике речи английского языка. Однако остается неясным, какие приемы должен использовать преподаватель для погружения обучающихся в целевые психические состояния. Напомним, что психическое состояние - это «отражение личностью ситуации в виде устойчивого целостного синдрома (совокупности) в динамике психической деятельности, выражающегося в единстве поведения и переживания в континууме времени» [18, с. 37]. Предполагаем, что деятельность учителя может быть объяснена на основе функционально-познавательного подхода.

\section{Основные положения функционально-познавательного подхода при обучении иноязычной монологической речи}

На втором курсе Института иностранных языков Сыктывкарского государственного университета имени Питирима Сорокина обучение монологической речи осуществляется в рамках функционально-познавательного подхода, разработанного и внедренного научно-методической лабораторией Коми государственного педагогического института под руководством профессора Б. П. Годунова. Функционально-познавательный подход нацелен на взаимосвязанное развитие у обучающихся иноязычных коммуникативно-речевых и познавательно-речевых способностей. Суть данного подхода «состоит в обеспечении усвоения и применения знаний общего, педагогического и специально-предметного характера в единстве. Для достижения такого единства необходима совместная работа механизмов внешнеречевой и внутреннеречевой деятельности. В этом случае предметная информация будет систематически “оречевляться” иноязычными средствами и постепенно превращаться в устойчивую и в то же время динамичную систему иноязычных функционально-познавательных структур. В итоге наступит такое иноязычное речевое состояние, когда функциональное и познавательное составляют две стороны одного явления» [7, с. 10]. При этом материальной основой и регулятором иноязычной речевой деятельности обучающихся должны стать познавательные процессы приобретения лингвистических и нелингвистических знаний, необходимых будущему учителю для практической работы и для саморазвития.

Обучение осуществляется на текстовой основе. При этом тексты используются в качестве стимулов, источников информации и опор, а также как средство косвенного управления грамматическим оформлением речевых поступков студентов. При работе над текстом используются функциональные грамматически-ориентированные упражнения, призванные обеспечить овладение семантической и формальной сторонами грамматических явлений в процессе их употребления и в единстве с логико-предметным содержанием иноязычной речи. Данные упражнения предполагают выполнение речевых действий двоякого рода: познавательно-речевых («Вспомни...», «Сравни...» и т.д.) и коммуникативно-речевых («Расскажи о...», «Выскажи свое мнение о...»).

Таким образом достигается необходимое единство в решении познавательных и коммуникативных задач: овладение грамматическим материалом происходит в процессе его коммуникативно-значимого использования в общей познавательной деятельности обучающихся. Комплекс функциональных грамматическиориентированных упражнений включает 7 групп упражнений:

1) на выборочное воспроизведение;

2) на перестановки;

3) на расширение и сокращение текста;

4) на содержательную трансформацию;

5) на аналогию;

6) на репродуктивное творчество;

7) профессионально ориентированные упражнения. 
На втором курсе существенно меняется значимость отдельных видов упражнений в общем объеме решаемых ими задач: первые три группы занимают все меньше места в аудиторной работе студентов, в то время как значение и удельный вес 4-6 групп последовательно возрастают. Именно эти упражнения помогают сделать шаг, который отделяет иноязычную условно-неподготовленную речь студентов от их иноязычной неподготовленной речевой деятельности.

Увеличение удельного веса функциональных грамматически-ориентированных упражнений на втором курсе связано со смещением акцента в обучении грамматическим явлениям на овладение семантикой. Грамматическая семантика понимается как комплекс отраженных связей и отношений между предметами и явлениями объективной действительности, зафиксированных с помощью языковых знаков. Грамматическая семантика выступает в качестве связующего звена между предметным содержанием и языковой формой и может служить средством косвенного управления действиями обучающихся, направленными на грамматическое оформление иноязычных высказываний, а также на употребление адекватного лексического материала.

\section{Доминирующий вид опыта при развитии умений монологической речи}

Рассмотрим особенности работы над группами функциональных грамматически-ориентированных упражнений на примере текста для второго курса Treating a Patient (Лечение пациента) по теме «Болезни и их лечение». Нина, студентка, проживающая в общежитии, заболела гриппом. Также Нина жаловалась на боль в правом боку и волновалась, что это может быть аппендицит. За ней ухаживала ее соседка по комнате, которая вызвала врача, сходила в аптеку за лекарством и пошла с Ниной на осмотр перед выпиской. Текст еще содержит небольшой диалог между Ниной и доктором.

Выборочное воспроизведение на втором курсе предполагает интеграцию преимущественно более мелких отрезков, представленных в разных частях текста, в отличие от выборочного воспроизведения целых фрагментов текста на первом курсе. Благодаря этому развивается умение отбирать из текста содержательный материал, необходимый для решения различных коммуникативных задач, и одновременно - грамматические средства для выражения этого содержания. Вместе с тем формируется навык грамматически правильного оформления высказывания и развиваются элементы умения инициативно употреблять коммуникативнозначимые грамматические явления. Доминирующий вид опыта в упражнениях данной группы - рациональный опыт студентов. Он проявляется в переживании таких психических состояний, когда личность использует ментальные операции анализа, конкретизации, выделения главного и второстепенного, выделения смысловых частей. Преподаватель может использовать следующий инвариант установки: Расскажите все, что вы знаете, о состоянии Нины в начале болезни и перед выпиской, о поведении Нины, о визите врача.

Упражнения на перестановки связаны на втором курсе в большей степени не с перемещением целых отрезков текста, а с включением отдельных содержащихся в них сведений в виде примечаний и отступлений.

Принципиально важным отличительным признаком упражнений 1 и 2 групп на втором курсе является то, что они берут на себя функции специальных тренировочных упражнений и соединяют их с присущими им самим функциями. Это позволяет уменьшить долю тренировочных грамматических упражнений и увеличить «экономичность» (Б. А. Лапидус) упражнений данных групп, а главное - поднять работу над грамматической стороной речи на качественно новый уровень. Доминирующий вид опыта в упражнениях данной группы - опыт информативной предрасположенности к речевому акту, при котором развитость словесноречевых представлений, то есть информативная насыщенность, позволяет студентам ориентироваться в речевом высказывании. Инвариантом установки может являться: Расскажите о болезни Нины. Начните свой рассказ с того, почему друзья за нее волновались.

При выполнении упражнений 3 группы речевой грамматический навык совершенствуется за счет того, что грамматический материал используется для решения более сложных мыслительных задач и в ином языковом окружении. Одновременно развивается умение самостоятельно переобозначить содержание других, ранее изученных текстов, грамматическими явлениями данного текста. Сокращение на втором курсе связано с содержательной компрессией. В упражнениях третьей группы все большее значение приобретает расширение усваиваемого текста за счет текстов, усвоенных ранее, а также за счет текстов, созданных самими студентами на базе ранее изученных текстов и ставших достоянием всей группы. Доминирующий вид опыта в упражнениях данной группы - опыт внутриречевой активности, выражающийся в потребности планирования и предвидения результата, развитости внутреннего плана действий. Приведем инварианты установок: Как вы думаете? О чем бы сообщила Нина подруге, если бы разговаривала с ней по телефону? Очевидно, она бы упомянула лишь главное (упражнение на сокращение).

Расширьте диалог Нины и доктора. Представьте, что доктор интересуется, часто ли у Нины болит голова, были ли у нее боли в боку раньше, делала ли она себе флюорографию в этом году. В конце разговора доктор сообщзает, при каком условии Нина быстро поправится (упражнение на расширение).

Упражнения на содержательную трансформацию предусматривают перегруппировку компонентов ситуации, заложенной в изучаемом тексте, установление новых отношений между компонентами ситуации. Способы осуществления трансформации на втором курсе следующие: изменяются условия развертывания событий данного текста, уменьшается или увеличивается количество действующих лиц или действующее лицо данного текста 
попадает в условия другого текста. Преподаватель лишь ориентировочно намечает границы для трансформации. Окончательно эти границы устанавливают сами студенты в процессе порождения речи. Следовательно, сами эти границы весьма подвижны и допускают значительное варьирование речевых действий обучающихся в устанавливаемых ими самими пределах. Благодаря этому речевое умение набирает силу, становится иерархически доминирующим по отношению к навыку и окончательно включает его в сферу своего действия. Доминирующий вид опыта в упражнениях данной группы - эмоционально-ассоциативный позитивно оцененный опыт студентов. «Он выражается в чувстве удовлетворения от предыдущих подобных иноязычных речевых поступков, превращающемся в особое состояние - эмоциональное предвосхищение» [20, с. 230]. Инвариантом установки может являться: Нина сейчас живет в общежитии. Как бы она лечилась, если бы жила дома с родителями?

В данном упражнении «вторичные» ситуации вызываются путем сталкивания фактов из разных текстов и содержания текстов с содержанием иноязычного речевого опыта студентов.

Упражнения на аналогию нацелены на сравнение фактов одного или нескольких текстов, а также на соотнесение содержания текста с сопоставимым содержанием общего и/или учебного опыта студентов. При выполнении заданий на аналогию студенты проявляют большую самостоятельность в определении общей меры использования содержания данного текста, ранее изученных текстов и личного опыта. Грамматическое оформление высказываний определяется не одной, а несколькими взаимодействующими тенденциями: ориентацией на грамматический материал данного текста, предрасположенностью к использованию грамматического материала ранее пройденных текстов, частотностью появления в прошлом иноязычном речевом опыте обучающихся тех явлений, которые могут быть использованы для построения сиюминутных высказываний. В итоге достигаются необходимая самостоятельность в грамматическом оформлении студентами высказываний и рассредоточенное употребление целевого грамматического материала, свойственное естественной коммуникации. Доминирующий вид опыта в упражнениях данной группы - поликультурный опыт, например: Расскажите о том, как вы болели в прошлом году.

В упражнениях на репродуктивное творчество материал учебного текста используется не столько для раскрытия основной мысли, сколько для ссылок, иллюстраций, уточнений, пояснений, аргументаций фактами и др. Как правило, не требуется указаний на использование грамматического материала. Доминирующий вид опыта в упражнениях данной группы - опыт ощущения личностной причастности, которая часто ощущается как отношение долженствования. Учитель может использовать следующий инвариант установки: Соседка Нины очень хочет, чтобы она быстрее поправилась. Как вы думаете, что она не разрешает Нине делать / заставляет Нину делать?

Профессионально-ориентированные упражнения предназначены для развития некоторых элементарных умений, необходимых будущему учителю иностранного языка. В учебной практике их целесообразно подключать ко всем группам комплекса. Доминирующий вид опыта в упражнениях данной группы - опыт в межличностных отношениях, который конкретизируется в ситуации лидерской реализации. На втором курсе предпочтение отдается действиям в соответствии с развернутой инструкцией: Нина поправилась. Она пришла на занятие и разговаривает с друзвями. Они задают вопросы о начале болезни, визите врача, о том, как Нина лечилась. Нина волнуется, что отстала от группы. Успокойте ее и расскажите, над чем вы работали это время, что уже сделали, предложите свою помощь.

Следует отметить, что не к каждому тексту прилагается полный комплекс упражнений, так как все тексты по своей значимости делятся на многоцелевые и одноцелевые. При этом учитывается ряд факторов: объем, тематическая насыщенность текста, представленность в нем изучаемого грамматического материала, характер восприятия текста студентами (визуально или аудитивно). Поскольку текст Treating a Patient является базовым тематическим текстом, работа над ним является долгосрочной, полной и включает все виды функциональных грамматически-ориентированных упражнений.

\section{Заключение}

Таким образом, мы приходим к следующим выводам. Все вышеперечисленные виды упражнений ведут к возникновению у обучающегося опыта самоутверждения, который вызывает возникновение ощущения удовлетворенности или неудовлетворенности результатом деятельности, а также потребность в рефлексии с целью самоутверждения.

Проведенное исследование позволило определить опыт как методическую категорию. Это переживания личности, которые проявляются в актуальных деятельностях и регулируют потенциальные деятельности человека. Преподаватель использует эмоциональный и интеллектуальный опыт студентов при обучении устной монологической речи на основе функционально-познавательного подхода.

Суть данного подхода состоит в следующем: единство в решении познавательных и коммуникативных задач; взаимосвязанное развитие у обучающихся иноязычных коммуникативно-речевых и познавательноречевых способностей; овладение грамматическим материалом происходит в процессе его коммуникативно-значимого использования в общей познавательной деятельности обучающихся; обучение монологу происходит на основе текста; при работе над текстом используются функциональные грамматически-ориентированные упражнения. 
В данном исследовании упражнения систематизированы по типам. Это упражнения на выборочное воспроизведение, на перестановки, на расширение и сокращение текста, на содержательную трансформацию, на аналогию, на репродуктивное творчество. Работа над целевым текстом предполагает последовательное выполнение функциональных грамматически-ориентированных упражнений. Профессионально ориентированные упражнения составляют особую группу и могут быть использованы на любом этапе работы над устной иноязычной речью.

Исследование показало, что при выполнении разных групп функциональных грамматически-ориентированных упражнений преподаватель может опираться на различные доминирующие виды опыта: в выборочном воспроизведении - на рациональный опыт студентов; в упражнениях на перестановки - на опыт информативной предрасположенности к речевому акту; в упражнениях на трансформацию - на эмоциональноассоциативный позитивно оцененный опыт студентов; в упражнениях на аналогию - на поликультурный опыт; в упражнениях на расширение и сокращение текста - на опыт внутриречевой активности; в упражнениях на репродуктивное творчество - на опыт ощущения личностной причастности. При выполнении профессионально-ориентированных упражнений, которые могут входить в любую группу, преподаватель задействует опыт в межличностных отношениях.

Работа по выявлению доминирующего вида опыта на занятиях по практике устной и письменной речи английского языка может быть продолжена в рамках других тем, а также аутентичных и учебных текстов с целью вызова у студентов целевых психических состояний.

\section{Список источников}

1. Богданова О. С. Логико-коммуникативные программы при обучении монологическому высказыванию // Иностранные языки в школе. 1988. № 5. С. 35-43.

2. Богданова Р. У. Развитие творческой индивидуальности субъектов образования. СПб.: Изд-во РГПУ им. А. И. Герцена, 2000. 220 с.

3. Буева Л. П. Человек: деятельность и общение. М.: Мысль, 1978. 216 с.

4. Выготский Л. С. Педагогическая психология. М.: АСТ; Астрель; Хранитель, 2008. 671 с.

5. Гальскова Н. Д., Гез Н. И. Теория обучения иностранным языкам. Лингводидактика и методика. М.: Академия, 2008. 336 с.

6. Гез Н. И., Ляховицкий М. В., Миролюбов А. А., Фоломкина С. К., Шатилов С. Ф. Методика обучения иностранным языкам в средней школе. М.: Высшая школа, 1982. 373 с.

7. Годунов Б. П. Функционально-познавательный подход к обучению иностранному языку на современном этапе. Сыктывкар: Изд-во Коми пед. ин-та, 2008. 111 с.

8. Голованова Н. Ф. Общая педагогика [Электронный ресурс]. URL: https:/studentam.net/content/category/ 4/116/127/ (дата обращения: 17.11.2020).

9. Драйден Г., Вос Дж. Революция в обучении. Научить мир учиться по-новому. М.: ПАРВИНЭ, 2003. 672 с.

10. Дьюи Дж. Демократия и образование. М.: Педагогика-Пресс, 2000. 382 с.

11. Заремская С. И., Слободчиков А. А. Развитие инициативной речи учащихся. М.: Просвещение, 1983. 127 с.

12. Зимняя И. А. Психологические аспекты обучения говорению на иностранном языке. М.: Просвещение, $1985.160 \mathrm{c}$.

13. Лесохина Л. Н. К обществу образованных людей... (Теория и практика образования взрослых). СПб.: Тускарора, 1998. 270 с.

14. Миньяр-Белоручев Р. К. Методика обучения французскому языку. М.: Просвещение, 1990. 224 с.

15. Новейший философский словарь [Электронный ресурс]. URL: https://rus-new-philosophy.slovaronline.com/ (дата обращения: 17.09.2020).

16. Ожегов С. И. Словарь русского языка [Электронный ресурс]. URL: https://slovarozhegova.ru/ (дата обращения: 15.09.2020).

17. Пассов Е. И. Теоретические основы обучения иноязычному говорению. Воронеж: Изд-во Воронеж. ун-та, 1983. 199 c.

18. Прохоров А. О. Определение понятия «психическое состояние» // Психология состояний: хрестоматия. М. - СПб.: ПЕР СЭ; Речь, 2004. С. 34-39.

19. Рогова Г. В., Рабинович Ф. М., Сахарова Т. Е. Методика обучения иностранным языкам в средней школе. М.: Просвещение, 1991. 287 с.

20. Трофимова Ю. И. Использование понятия «опыт» в объяснении процесса овладения иностранным языком // Человек. Культура. Образование. 2019. № 1 (31). С. 226-232.

21. Христофоров С. В. Опыт как педагогическая категория // Вестник Оренбургского государственного университета. 2005. № 7 (45). С. 180-184.

22. Шацкий С. Т. Избранные педагогические сочинения: в 2-х т. / под ред. Н. П. Кузина, М. Н. Скаткина, В. Н. Шацкой. М.: Педагогика, 1980. Т. 1. 304 с.

23. Энциклопедия практической психологии [Электронный ресурс]. URL: https://www.psychologos.ru/articles/ view/psihologos (дата обращения: 17.09.2020). 


\section{Информация об авторах | Author information}

RU Сердюк Елена Владимировна ${ }^{1}$, к. пед. н.

${ }^{1}$ Сыктывкарский государственный университет имени Питирима Сорокина

EN Serdyuk Elena Vladimirovna ${ }^{1}, \mathrm{PhD}$

${ }^{1}$ Pitirim Sorokin Syktyvkar State University

${ }^{1}$ serdukelena@mail.ru

\section{Информация о статье | About this article}

Дата поступления рукописи (received): 11.11.2020; опубликовано (published): 30.12.2020.

Ключевые слова (keywords): коммуникативный опыт; устная иноязычная речь; студенты педагогического направления; функционально-познавательный подход; грамматически-ориентированные упражнения; communicative experience; oral foreign-language speech; pedagogical students; functional-cognitive approach; grammar exercises. 